\title{
Cloud Storage as an Effective Student Information Storage System for Global Access
}

\author{
S. Mari, K. Thiayagarajan, S. JaniferVinnarasi
}

\begin{abstract}
Data Systems (IS) execution in advanced education is an enormous speculation. Such speculations are required to bring expanded proficiency and viability, just as better quality administrations to partners. Our writing search didn't discover understudy data the board frameworks (SIMS) in Ethiopia or comparative low-salary nations. This exploration is work in progress. It endeavors to connect the writing hole for use and achievement variables of SIMS in a college setting of low salary nations. The investigation will address the examination question: what determinant components add to the achievement or disappointment of IS in advanced education establishments in Ethiopia, with specific reference to SIMS? The examination utilizes DeLone and McLean (1992, 2003) IS Success Model to recognize the components of IS achievement when applied to SIMS. We additionally research two new develops top administration backing and client bolster that were discovered important in the examination setting.

Keywords: Information management framework for students, higher education institutions, IS Performance Model, reliability of information, program quality, user support, top management support
\end{abstract}

\section{INTRODUCTION}

Data framework is characterized as a 'gathering of subsystems characterized by practical or authoritative limits (Iivari, 1991). It bolsters basic leadership and control in associations (Lucas, 1981) by using data innovation to catch, transmit, store, recover, control, or show data utilized in at least one business procedures' (Alter, 1996). Like any advanced business part, Higher Education Institutions (contracted as HEIs) need to accomplish and upgrade quality in its working. But these institutions face challenges in the process of attaining the objective of becoming better quality HEI. McClea and Yen, (2005) stated that:"In this sector the challenge begins with the institution's admission department. The admissions department functions as the delivery point for quality inputs, which should eventually become even higher quality outputs. The department, then, must collect significant amounts of data about students as well as maintain the ability to effectively analyze and transform the data into pertinent

Revised Manuscript Received on December 30, 2019.

S. Mari, Assistant Professor, Department Of Science \& Humanities, Bharath Institution Of Higher Education And Research TamilNadu,India.Email: maripalani09@gmail.com

K. Thiayagarajan, Assistant Professor, Department Of Science \& Humanities, Bharath Institution Of Higher Education And Research TamilNadu,India.Email: thiyagu768@gmail.com

S. JaniferVinnarasi Assistant Professor, Department Of Science \& Humanities, Bharath Institution Of Higher Education And Research TamilNadu,India.Email: mjjaa24@gmail.com information. This develops a new function for the admission department to perform - information technology. Information technology presently represents a critical success factor for numerous organizations. Higher educational institutions fall into this category and have sought the status of first movers in relation to the development and implementation of information technology throughout the areas of academia" (McClea and Yen, 2005).[1]-[5] The above points signify that information system has become an important part of the institution of higher education and one of the major areas where information systems plays a key role is the Admissions Department. SIMS is a software application for educational establishments to manage student data that includes student admission information, course information on academic grades and other student-related dataThe strategic approaches and forms, and the data that aides basic leadership in huge territories of the foundation, associate with and get from these data frameworks (Suwardi, 2007). Its execution is perhaps the biggest speculation (Suwardi, 2007) in advanced education establishments. The benefits of telecommunications in higher education admissions stem from the critical need to improve efficiency, improve productivity and reduce costs while growing requirements and enhance the quality of students participating in education programmes. (McClea and Yen, 2005).[6]-[10]

Collecting, analyzing and transforming a growing student related data into pertinent information is difficult without the development and implementation of ICT-supported IS. Therefore, Universities and Colleges are currently investing on the development and implementation of SIMS to meet the requirements. Such venture on data frameworks is required to bring expanded productivity and adequacy just as better quality administrations to the clients in the zone. In this way, the estimation of data frameworks achievement or viability is basic to our comprehension of the worth and adequacy of IS the board activities and IS ventures (DeLone and McLean, 2003). In such manner, there ought to be research to recognize factors that add to the achievement or disappointment of SIMS in HEIs in Ethiopia and other creating nations.[11]-[15] The purpose of this work is to contribute to addressing the success factors of the information system for the implementation and use of the information system in general, and SIMS in specific in Ethiopia. university system 


\section{Cloud Storage as an Effective Student Information Storage System for Global Access}

from a national perspective, an area in which our search of the literature yielded little evidence of research activities. As it is expressed by Anakwe, et al. (1999) numerous concentrates on IS usage achievement have been attempted yet not many have focused on Least Developed Countries (LDCs). They additionally included that "there is developing worry that usage and use of IS are being embraced with lacking thought of financial, social and political challenges. Distinguishing the determinants for IS accomplishment inside these varying settings is significant in LDCs. This exploration venture will in this manner endeavor to conquer any hindrance in the writing between the Information System use and IS achievement factors for its utilization in a college setting of low salary nations, for example, Ethiopia. The examination will address the exploration question: what determinant components add to the achievement or disappointment of IS in advanced education organizations of Ethiopia with specific reference to SIMS? The investigation utilizes De Lone and McLean model to distinguish the components of IS achievement when applied to SIMS with regards to a HEIs .Not with standing the sex builds of the first model, i.e., data quality, framework quality, use, client fulfillment, singular effect, authoritative effect; client backing and top administration backing are viewed as significant to the examination region and included as directing elements. Testing whether data frameworks achievement models like De Lone and MacLean's can be reached out to examine SIMS's prosperity inside a low salary nation setting is the enthusiasm of the investigation. The paper is organized in four sections. The first section develops the basis for the case study by introducing St. Mary's University College and its SIMS. The second section deals with the theoretical framework to be used in investigating the success or failure of SIMS. This section will present the De Lone and McLean (1992) information system success model, additional constructs to be added in the model which are determinant factors for the IS success in our context, definition of each construct and the hypothesis set for each of the constructs. The third section presents the methodology to be followed in studying the IS success factors. In this section the method to be applied, measurement instruments, and sample size as well a sdata collection techniques will be discussed. In the last section we present our concluding remarks and indicate the expected results and contributions of the study.[16]-[20] Conceptual Model

System Quality Individual Impact

\section{MOTIVATION AND STUDY BACKGROUND}

Investment in the SIMS field is a high priority in the case of the Ethiopian HEIs. This is partly due to the recent extension of HEIs and the rise in student enrolment. As recent as 2005, there were only 9 public HEIs in Ethiopia. In the last three to four years, 13 new public universities have been established and made functional, increasing the number of public HEIs to 22.. In addition to this about 250 private higher education institutions have been established in the past ten years, most of which offer diploma and certificate programs. About 55 of the 250 private higher education institutions offer degree programs and 2 of the 250 offer post graduate programs. Therefore, a total of 263 new public and private higher education institutions have been established In the last 10 years. It increased the total number of both public and private people HEIs to 272. Partly because of this expansion, the average five year growth in tertiary level enrollment reached $27 \%$. This expansion brought significant increase in student enrollment. In order to cope up with such expansions in student enrollment, institutions of higher education are making investment in the development and implementation of IS and it is a most recent phenomenon in the case of Ethiopia. Appropriate evaluation of these systems remains an important agenda for higher education management if they are to see a good return for their costly investment. Thus, our motivation is to conduct this study to help identify determinant factors that contribute to the success or failure of IS implementation and use in HEIs with particular reference to SIMS in Ethiopia using a specific case. We selected St. Mary's University College mainly because of the experiences one of the co-authors as a staff member at the university college during its system development and implementation. Currently the researcher is also a primary user of the system.

St. Mary's University College is a private HEI which was established in the year 2000. It is one of the two private higher education institutions that offer post graduate programs. It also offers degree, diploma and certificate programs inconventional mode (Regular and Extension face-to-face classes) as well as in distance education mode. There are a total of 22 departments in both conventional and distance education mode that offer degree, diploma and certificate programs. The total number of students in both modes is 40,393, of which 16, 833 are degree students, with 20,545 diploma students and3,015 Certificate students in both conventional and distance programs. The total number of full time academic staff is 206 , and that of administrative staff is 778.SIMS for the University College is developed in-house based on the requirement specification of the Registrar's Office. The system is developed using PHP programming language with MySQL database. Apache Server is used to configure the system. After properly testing the SIMS it was implemented successfully in September 2008. The system supports functions including storing and processing students' admission data, handling course registration, scheduling classes, entering and processing grades, generating grade reports and transcripts, processing graduation related data and generating statistica lreports of different kind for multiple purposes. 
SIMS interacts with an independent Exam Correction Software to automatically update its database with new additions and changes of course title, course code, and student data. It also automatically imports grades from the Exam Correction Software. SIMS also interacts with other three packages. One package is software that is used by 16 Coordination Centers of Distance Education at different regions to process and forward results of projects and term papers electronically to the main Registrar Office. SIMS automatically imports the results from the system. The other package is Exam Attendance Information System which is used by Exam Unit of Distance Education and Departments to incorporate and track student attendance on exam for the courses registered. SIMS also interacts with this system to automatically import exam attendance information. There is also finance software which is known as PayCol. SIMS automatically feeds students' data to Pay Col system.

Users of the system include all staff members of Registrar Office, finance office as well as the teaching staff in different departments. The total number of users of the system is about 292. The total number of students supported by the system, asit is stated above, is 40,393 . The system has been in use for the past two and half years. At the initial stage of implementation there was data mismatch problem (including student data and course related data) encountered during data migration from theold system to the new one. It took a couple of months to solve this problem. There is no other major problem encountered except the minor ones which were corrected rather painlessly.

\section{THEORETICAL FRAMEWORK}

\section{A. Background on the Model}

Research in the course of recent decades has brought about various ways to deal with the assessment of IS achievement. Some of them incorporate framework utilization, Information Value, client fulfillment and all the more as of late help quality. Such fluctuated ways to deal with IS achievement measures recommend absence of understanding in regards to the subject of what comprises IS achievement. One of the regularly refered to papers in the writing is that of DeLone and McLean (1992). In their paper, the creators integrated 100 exact IS achievement measures (distributed somewhere in the range of 1981 and 1987) and proposed a model that consolidates a few individual components of accomplishment into a general model of IS achievement. DeLone and McLean presented six significant measurements or classifications of IS achievement - framework quality, data quality, use, client fulfillment, singular effect and hierarchical effect. As per DeLone and McLean (2003), in the IS Success Model, "frameworks quality" measures specialized achievement; "data quality" measures semantic achievement; and "use, client fulfillment, singular effects," and "authoritative effects" measure viability achievement. As they have explained, an is first made, containing different highlights, which can be described as displaying different degrees of framework and data quality. Next, clients and administrators experience these highlights by utilizing the framework and are either fulfilled or disappointed with the framework or its data items. The utilization of the framework and its data items at that point effects or impacts the individual client in the direct of their work, and these individual effects by and large outcome in hierarchical effects. As per Gable et al. (2003), the develops/proportions of the Delone and McLean model gave an all encompassing perspective over the association-from a top the board point of view, to that of information section officials' - and gave a nitty gritty order of accomplishment measurements.

As it is expressed in the presentation DeLone and McLean Information System Success Model is utilized as a hypothetical structure for the examination. This is basically on the grounds that the DeLone and McLean structure is broadly acknowledged as one of the more complete IS assessment systems and has been utilized widely in exact research (Ballantine et al., 1996). The model likewise empowers us to assess the achievement of IS at various levels framework, individual and authoritative.[21]-[25]

\section{RESULT \& DISCUSSION}

Framework quality is a proportion of the data handling framework itself. Most measures in this class tap engineeringoriented execution qualities. It comprises of execution attributes of the frameworks which incorporate asset usage, unwavering quality, reaction time, simplicity of terminal use, information precision, dependability, fulfillment, framework adaptability and convenience. On account of Student Information Management System, usability, reaction time, correspondence with other framework, adaptability and simplicity of learning are the significant characteristics that are esteemed by clients of the Student Information Management System. Seddon and Kiew (1994) found in their way examination that data quality and framework quality are critical determinants of generally speaking client fulfillment. The Technology Acceptance Model (Davis et al., 1989) predicts that apparent straightforwardness of utilization, as a part of framework quality (DeLone and McLean, 1992) is a critical immediate and circuitous determinant of utilization, the aberrant impact being directed through apparent handiness. It is normal in this manner, that the higher the framework quality, the better the achievement of Student Information Management System (SIMS) as far as improved use and client fulfillment. This is spoken to by the accompanying theory.

H1a: SIMS quality will be emphatically identified with the utilization of SIMS.

H1b: SIMS quality will be emphatically identified with SIMS client fulfillment. 


\section{Cloud Storage as an Effective Student Information Storage System for Global Access}

Data quality speaks to proportions of data frameworks yield. It is an element of the estimation of the yield created by a framework as saw by the client. Commonplace measures here incorporate exactness, accuracy, money, yield practicality, dependability, culmination, brevity, organization and pertinence (Bailey and Pearson, 1983). Different creators likewise included understandability, report convenience, adequacy, opportunity from inclination, similarity, and quantitativeness. In this examination, data quality is considered as having attributes of precision, yield practicality, culmination, yield clearness and configuration.The framework ought to have the option to give definite data about the understudy including, affirmation status, scholastic status, complete courses taken and staying, all out terms visited and remaining, and grade lacks. Clients ought to affirm that the data gave is precise, convenient gave, dependable, complete, and showed in suitable organization. A positive conformance of these attributes by the clients suggests that there is viability in the utilization of SIMS. Seddon and Kiew (1994) likewise expressed that data quality is a critical determinant of in general client fulfillment. This prompts the accompanying theory.

H2a: SIMS data quality will be emphatically identified with SIMS use.

H2b: SIMS data quality will be emphatically identified with SIMS client fulfillment.

Top the board backing is conceptualized as the association and interest of the official or toplevel the executives of the association in IT/IS exercises (Jarvenpaa and Ives, 1991, previously, there are various investigations that approved the positive connection between top administration support and IS achievement. Lord and Teo, (1996) discovered top administration bolster encouraged the fruitful organization of key IS applications, while absence of top administration bolster was found to repress its vital utilization/IS. Igbaria et al., (1997) tried an auxiliary condition model on individualized computing factors in little firms and discovered administration bolster has positive direct impacts on seen helpfulness and saw usability. Ang et al., (2001) inspected 47 Malaysian open part organizations on IT use to help absolute quality the executives (TQM). In this examination top administration support for IT applications is seen as the most elevated indicator of IT use. Every one of these discoveries demonstrated that top the executives backing has huge impact on IS achievement. Every one of these discoveries empower us to create theory 3 which is expressed as pursues. H3: The impact of framework quality and data quality on SIMS use and client fulfillment is the positive capacity of top administration support.

Client backing is mostly worried about the specialized help and help given to clients regarding working the data frameworks in the association (Hussein, et al., 2005). As it is expressed above there are numerous investigations led in the refered to in Hussien, et al., 2007).As it is expressed

territory which affirmed solid connection between client backing and achievement in client figuring. In a mechanized domain where there is ICT based Student Information Management System we accept that specialized help to clients of the frameworks is urgent.

Clients will in all likelihood look for help in utilizing the frameworks in their every day activities. In view of the confirmations, it is conceivable to theorize the connection between client support and IS accomplishment as pursues:

H4: The impact of framework quality and data quality on SIMS use and client fulfillment is the positive capacity of client support. Use alludes to the beneficiary utilization of the yield of a data framework. A portion of the qualities used to quantify data use by various creators include: measure of utilization/length of utilization, number of request, number of capacities utilized, number of records accessed, frequency of access, number of reports generated, regularity of use, use for intended purpose of use and motivation to use. In our context "Use" measures everything including data entry, data manipulation (edit, delete), grade report and transcript generation, statistical report generation, retrieving and any student related information and

providing it to a third party. In this case, use is not voluntary. Therefore, for this study use for intended purpose, extent of use and number of system's functions used are considered the most appropriate.. Disharmony hypothesis by Fishbein and Ajzen (1975, refered to in DeLone and McLean, 1992), proposes that IS use prompts client fulfillment. The discoveries of meta analysis led by Bokhari (2005) lead to the decision that there exists a "medium" and huge positive connection between framework utilization and client fulfillment (i.e., $r=0.2555$ ). Notwithstanding these, SIMS use is an immediate precursor of individual effect factors. In this way, considering these connections the accompanying theory can be made for SIMS use.

H5a: SIMS utilize has positive association with and prompts client fulfillment $\mathrm{H}$ 6: SIMS use will be decidedly identified with individual effects of the SIMS. Client fulfillment can be characterized as the degree of which clients accept the data framework accessible to them meets their data and framework prerequisites (Baroudi et al., 1983). Client fulfillment is a regularly utilized proportion of framework achievement.

A portion of the attributes which are considered as determinants of client fulfillment include: generally fulfillment, data fulfillment - contrast between data required and got, pleasure, programming fulfillment, and basic leadership fulfillment. In our unique circumstance, client fulfillment is a significant methods for estimating the degree of fulfillment of framework clients, i.e., employeesof the university college while using the system in the process of data entry, data manipulation, report generation, information retrieval and provision to the required body (including the management, 
Ministry of Education, Education Bureaus, students, different departments, coordination centers). Some of user satisfaction characteristics which are relevant tothe study are overall satisfaction level, extent of dependence on the system, increased status of employees, personal benefitsgained, assurance of usefulness of the system.

Baroudi et al., (1986) propose that if client fulfillment is translated as a demeanor, the Theory of Reasoned Action (Fishbein and Ajzen, 1975, refered to in DeLone a nd McLean, 1992) bolsters the model that client fulfillment will impact goals to utilize the framework and genuine use. It is normal that the level of client fulfillment can influence the measure of utilization of SIMS. Furthermore, since client fulfillment is an immediate forerunner of individual effect factors the previous influences the last mentioned. Hence, in view of these connections we set up the accompanying theories in connection to client fulfillment build.

H5b: SIMS client fulfillment will be decidedly identified with the utilization of SIMS.

H6: SIMS client fulfillment will be decidedly identified with individual effects of the SIMS.

The individual effect measurement is characterized by DeLone and McLean (1992) as "the impact of data on the conduct of the beneficiary". A portion of the attributes which are considered as determinants of individual effect include: data getting, learning, precise understanding, data mindfulness, data review, issue distinguishing proof, choice adequacy, improved singular profitability, and undertaking execution. Those characteristics which are most relevant to the study are performance related issues. According to Bokhari (2005), "The prime purpose of introducing IS into an organization is to improve not only individual decision-making performance but overall organizational efficiency and effectiveness. The expected gains in terms oforganizational goals through IS implementation and adoption are concerned with the success of the system". Therefore, theimpact on individual performance should eventually have some organizational impact. Therefore, the possible hypothesesthat can be built is the following:

H7: The impact on individual performance will be related to the organizational impacts of SIMS

\section{METHODOLOGY}

An overview instrument will be utilized to assemble information to test the connections appeared in the examination model. Essential clients of the framework at the college school will be reviewed with the end goal of requesting their perspectives and evaluation of the framework being utilized. The objective populace incorporates all staff individuals from the Registrar Office and Finance Office, the school personnel and the top the executives of the college school. The all out number of respondents is relied upon to be 292. Three corresponding techniques will be utilized for gathering essential information: poll, meet and direct perception of Student Information Management System and administrations. The inquiries are drawn from recently approved instruments and adjusted to the present examination setting. Data on the instruments or measures is exhibited in Appendix A. The investigation will utilize perceptual measures to catch information on IS achievement factors. Perceptual estimates are worthy measures in most study explore. A five-point Likert scale will be utilized to speak to the reactions of the subjects.

\section{CONCLUSION AND FUTURE RESEARCH}

The findings of this work in progress study will demonstrate the importance of IS success factors in determining the effectiveness of SIMS applications in the higher education environment. This paper will make four significant commitments. In the first place, it offers understanding of estimating the achievement of IS with regards to advanced education organizations of low pay nations, for example, Ethiopia. Second, it indicates which factors can become dominant in the success of a system, especially when it is developed in-house. Third, the identification of success factors will help the top management to focus on these factors and make the necessary interventions. Fourth, it will open an opportunity and lessons learned for further research in the area. In general, this will be both a theoretical and practical contribution to the field of IS success when implemented in HEIs; inparticular HEI in low income countries may benefit from the lessons learned. Since this is to a greater extent a model structure study, a piece of our future arrangement is to lead observational research to approve the builds displayed in the model.

\section{REFERENCES}

1. Vasanthi, S. \& Rabiyathul Basariya, S. 2019, "Influence of value analysis and cross training in industry", International Journal of Engineering and Advanced Technology, vol. 8, no. 6, pp. 1810-1811.

2. Velvizhi, R., Sri Gowtham, S. \& Jeya Priya, D. 2019, "Examination of early feedbacks for effective product retailing on E-commerce websites", International Journal of Engineering and Advanced Technology, vol. 8, no. 6 Special Issue 2, pp. 703-706.

3. Anuradha, C., Pothumani, S. \& Kavitha, R. 2019, "A novel method towards E-commerce", International Journal of Engineering and Advanced Technology, vol. 8, no. 6 Special Issue 2, pp. 535-538.

4. Thomas, J. \& Rabiyathul Basariya, S. 2019, "A study on the issues of financial ratio analysis", Indian Journal of Public Health Research and Development, vol. 10, no. 3, pp. 1079-1081.

5. Ramachandran, S. \& Rabiyathul Basariya, S. 2019, "Online marketing - study on customer satisfaction and relationship", Indian Journal of Public Health Research and Development, vol. 10, no. 3, pp. 1072-1078.

6. Priya, R., Vinothini, G. \& Cor Jesu, C.D. 2019, "The mentor-protégé relationship for professional growth", Journal of Advanced Research in Dynamical and Control Systems, vol. 11, no. 9 Special Issue, pp. 1110-1119.

7. Jannifer Rani, N., Bina Pani, S. \& Nimisha, N.S. 2019, "A study on money back polices available in LIC", Journal of Advanced Research in Dynamical and Control Systems, vol. 11, no. 9 Special Issue, pp 833-839. 


\section{Cloud Storage as an Effective Student Information Storage System for Global Access}

8. Saillaja, V., Jhansi Rani, K. \& Catherine, R. 2019, "Global marketing management planning and organization", Journal of Advanced Research in Dynamical and Control Systems, vol. 11, no. 9 Special Issue, pp. 489-493.

9. Saillaja, V., Jhansi Rani, K. \& Catherine, R. 2019, "The new phase of marketing information system", Journal of Advanced Research in Dynamical and Control Systems, vol. 11, no. 9

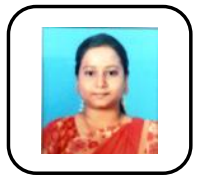
Special Issue, pp. 482-488.

10. Thoufiqulla \& Raju, D.V. 2019, "Perception of indian investor towards investment in mutual funds with special reference to mip funds", Journal of Advanced Research in Dynamical and Control Systems, vol. 11, no. 5, pp. 177-183.

11. Jasmine, K.R.M. \& Basariya, S.R. 2018, "A study on the customers benefits on mutual funds", International Journal of Civil Engineering and Technology, vol. 9, no. 4, pp. 45-48.

12. Vasanthi, S. \& Basariya, S.R. 2019, "Pros and cons of on the job training versus off the job training", International Journal of Scientific and Technology Research, vol. 8, no. 10, pp. 671-674.

13. Pavithra, J. \& Ganesan, M. 2016, "A study on awareness and impact of micro-financial schemes", International Journal of Applied Business and Economic Research, vol. 14, no. 8, pp. 5449-5460.

14. Pavithra, J., Dilli Babu, P. \& Ambuli, T.V. 2014, "A study on budgetary control at Maruti Service Masters, Chennai", International Journal of Applied Business and Economic Research, vol. 12, no. 2, pp. 151-161.

15. Gunaraja, T.M. \& Venkatrama Raju, D. 2018, "Determining factors of organisational climate with reference to leadership styles", International Journal of Mechanical Engineering and Technology, vol. 9, no. 9, pp. 1327-1332.

16. Gunaraja, T.M. \& Venkatrama Raju, D. 2018, "The role of job satisfaction and training of employees in determining organisational climate of a selected industry", International Journal of Civil Engineering and Technology, vol. 9, no. 8, pp. 1266-1269.

17. Aarathy, T.S. \& Raju, D.V. 2018, "Performance appraisal and its effects on employees with respect to it sector in Chennai city", International Journal of Civil Engineering and Technology, vol. 9, no. 6, pp. 1535-1538.

18. Aarathy, T.S. \& Raju, D.V. 2018, "Employee perception towards performance appraisal system in IT sector", International Journal of Mechanical Engineering and Technology, vol. 9, no. 5, pp. 131-135.

19. Porselvi, W., Jublee, D. \& Sivanesan, G. 2018, "A study on factors influencing adoption of technology and innovation in banking industry, tamilnadu, India", International Journal of Mechanical Engineering and Technology, vol. 9, no. 5, pp. 789-800.

20. Akessa, G.M. and Dhufera, A.G., 2015. Factors That Influences Students Academic Performance: A Case of Rift Valley University, Jimma, Ethiopia. Journal of Education and Practice, 6(22), pp.55-63.

21. Miller, G. and Shih, C.C., 1999. A faculty assessment of the academic rigor of on-and off-campus courses in agriculture. Journal of Agricultural Education, 40, pp.57-65.

22. Tsinidou, M., Gerogiannis, V. and Fitsilis, P., 2010. Evaluation of the factors that determine quality in higher education: an empirical study. Quality Assurance in education, 18(3), pp.227-244.

23. Farooq, M.S., Chaudhry, A.H., Shafiq, M. and Berhanu, G., 2011. Factors affecting students' quality of academic performance: a case of secondary school level. Journal of quality and technology management, 7(2), pp.1-14.

24. Fitsilis, P., Gerogiannis, V. and Anthopoulos, L., 2014. Ontologies for software project management: a review. Journal of Software Engineering and Applications, 7(13), p.1096.

25. Adams, J.D. and Jaffe, A.B., 1996. Bounding the effects of R\&D: an investigation using matched establishment-firm data(No. w5544). National bureau of economic research.

\section{AUTHORS PROFILE}

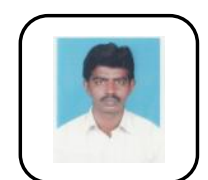

S. Mari, Assistant Professor, Department Of Science \& Humanities, Bharath Institution Of Higher Education And Research TamilNadu,India

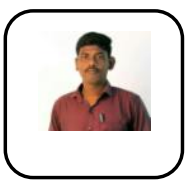

K. Thiayagarajan, Assistant Professor, Department Of Science \& Humanities, Bharath Institution Of Higher Education And Research TamilNadu,India
S. JaniferVinnarasi Assistant Professor, Department Of Science \& Humanities, Bharath Institution Of Higher Education And Research TamilNadu 